I Universidade Federal do Sul da Bahia (UFSB), Porto Seguro, BA, Brasil

lacsi945@gmail.com

II Universidade Federal do Sul da Bahia (UFSB),

Porto Seguro, BA, Brasil

linafariar964@gmail.com

\title{
ENSAIO DE LEITURA: INTERSECÇÕES E CORRELAÇÕES NO MUNDO DO TRABALHO E DO CUIDAR (BRASIL/FRANÇA)
}

\author{
Now a man is born to go a lovin \\ A woman's born to weep and fret \\ To stay at home and tend her oven \\ And drown her past regrets \\ In coffee and cigarettes. \\ "Black Coffee" (Webster \& Burle, I948)
}

Ao debater experiências femininas, contemporâneas e históricas, a obra Gênero e trabalho no Brasil e na França: perspectivas interseccionais (Abreu, Hirata \& Lombardi, 20I6) examina, sob múltiplos olhares, os desafios e obstáculos enfrentados na busca de reconhecimento de seu papel no interior da divisão sexual do trabalho. Não se trata, como dizem as organizadoras da coletânea, sociólogas Alice Rangel de Paiva Abreu, Helena Hirata e Maria Rosa Lombardi, propriamente de uma comparação entre países "tão difíceis de comparar". A bem dizer, a obra, publicada oportunamente na Coleção Mundo do Trabalho, sob a coordenação de Ricardo Antunes, fornece uma visão geral das complexas relações entre trabalho, cuidado, cidadania, ética, política do corpo e políticas sociais no Brasil e na França. É como se as comparações ficassem um pouco por conta do leitor, munido de um arsenal de excelente qualidade, informativo e analítico, sobre as problemáticas das desigualdades de gênero, das relações sociais de sexo e de uma cartografia sobre o lugar das mulheres e dos homens no mundo, aliás, nos mundos do trabalho.

A obra está dividida em seis partes (Entrecruzar as desigualdades; Medir as desigualdades; Trabalho e uso do tempo; O gênero das carreiras artísticas e científicas; Cuidado, dinâmicas familiares e profissionais; Cuidado, políticas sociais e cidadania) e 23 capítulos. Os temas se estendem às relações sociais de desigualdade no cuidar; às experiências do feminino frente a desafios e múltiplas possibilidades e conquistas profissionais; às dinâmicas familiares; 
ao cuidado em domicílio e às relações informais de emprego; aos programas e políticas de formalização do trabalho feminino (em especial, no tocante a tempo de trabalho, remuneração e relações de exploração, discriminação e opressão).

O impulso imediato para a consecução do livro surgiu da rica experiência - refletida nas inúmeras contribuições ao volume - no colóquio "Trabalho, cuidado e política social: Brasil-França em debate", realizado em agosto de 20I4, no Brasil. Pesquisadores brasileiros e franceses já têm trabalhado juntos sobre o tema por longo tempo. Se um primeiro intercâmbio internacional de peso sobre trabalho e gênero remete a 2007, no Brasil, por ocasião da colaboração de pesquisadores e pesquisadoras do laboratório francês Mage, deve-se mencionar que, além desse impulso inicial, somou-se o encontro "Teorias e Práticas do Cuidado" (Théories et Pratiques du Care: Comparaisons Internationales), promovido pela Universidade Paris Descartes, em junho de 20r3. O livro a que ora nos remetemos é, de tal modo, o resultado caprichado de tais experiências conjuntas. Valeu o esforço de atualização e ampliação do debate teórico sobre as relações de trabalho e gênero, bem como sobre o lugar de mulheres (e homens, ça va sans dire) no mundo do trabalho no Brasil e na França. Os capítulos da obra, escritos por sociólogas, antropólogas, economistas e demógrafas, permitem aos leitores conhecer, analisar e comparar as múltiplas situações de desigualdade nos usos do tempo; de discriminação nas dinâmicas de trabalho; de imbricações nas relações entre gênero, sexo, raça, cor e posição social. Permitem, ainda, um olhar amplo e crítico sobre os tipos de cuidado e as "operações complexas" que envolvem essa atividade, "algo difícil de compreender e identificar", nas palavras de Danièle Kergoat (2016).

No caso de obras coletivas, o desafio de "compreender e identificar" pede a compreensão especial do leitor, particularmente se é visitante recente que prepara um trabalho de conclusão de curso. O primeiro passo das organizadoras para cativar tais visitantes está na capa, de forte apelo histórico: moças aprendizes de datilografia, em fotografia de I902. (Em contraponto, a segunda capa reproduz jovens operadores de um call center, Ioo anos depois). A orelha da segunda capa traz uma apreciação certeira sobre "reconfigurações de gênero, raça e classe", de Renata Gonçalves, professora da Unifesp. Segue-se na quarta capa uma vinheta, ao modo de uma carta-convite, redigida por Miriam Nobre, pesquisadora e coordenadora da Marcha Mundial das Mulheres: em tom poético, "a presença do feminismo nas ruas, redes e roçados...". As boas-vindas têm sequência com Prefácio de Tatau Godinho, personagem-chave, no país e no exterior, na defesa dos direitos da mulher ao trabalho e à autonomia; uma página de "Agradecimentos", assinados pelas organizadoras e colaboradoras do naipe de produção (em que se incluem Bila Sorj, Margaret Maruani e Nadya Araujo Guimarães), que revela a rede de apoio cuidadosamente tecida com instituições do Brasil e França; e por fim a página de "Introdução", assinada por toda a equipe. 
É tempo de avançarmos pelos caminhos seguros, trilhados por três dezenas de autoras e quatro autores convidados, a desproporção de gênero revelando, a bom entendedor, que está pronto a adentrar (nunca tarde demais) uma Terre des femmes.

I

A discussão sobre o cuidado, o care anglo-saxão - o anglicismo transposto para todo o território europeu, com algumas exceções como Portugal -, ocupa duas partes inteiras como fecho da obra. São elas a Parte V e a Parte VI, já nomeadas acima. Ali se discutem, em quase uma centena de páginas, as imbricações do care em relação às dinâmicas familiares e profissionais e, sob este último as pecto, a interação entre profissão, mercado de trabalho, políticas sociais e cidadania. O fecho reservado às duas partes finais da obra é muito feliz, pois justamente o primeiro capítulo convida à leitura sobre o cuidado e sua imbricação (termo caro a Danièle Kergoat (20I6)) nas relações sociais. De fato e de direito (invariavelmente contra a mulher), a relação histórica entre homens e mulheres ao longo dos séculos jamais dissociou trabalho e gênero do cuidado, ou do cuidar, particularmente do cuidar doméstico - tornando sólida e quase imbatível, também séculos afora, a assimetria de gênero (capítulo 8) e a dominação.

Esse é um ponto de honra para toda a obra. A responsabilidade das mulheres pelas tarefas concretas de cuidar do outro (a criança, o idoso), combinada aos valores associados à feminilidade, aprofundaram, historicamente, as desigualdades e discriminações no mundo do trabalho. Este será o recorte, histórico e sociológico, de textos teóricos ou analíticos e sólidos estudos empíricos, em que se destacam os capítulos: "O cuidado e a imbricação das relações sociais”, de Danièle Kergoat, já citado (capítulo I); “Carinho, limpeza e cuidado: experiências de migrantes brasileiras", de Adriana Piscitelli (capítulo 4); “O cuidado em domicílio na França e no Brasil", de Helena Hirata (capítulo I6); "Cuidados e confiança", de Ângelo Soares) (capítulo I8); "Política da presença: as questões temporais e sexuadas do cuidado", de Marc Bessin (capítulo 20); "Políticas públicas diante do envelhecimento", de Guita Debert (capítulo 2I) e "O cuidado e a nova agenda de combate à violência no Brasil", de Bila Sorj (capítulo 22). Nesses e em outros capítulos, seja a ênfase sobre o care ou sobre o trabalho, ressalta a noção de que o que está em jogo é a imbricação entre esses fenômenos. Todo indivíduo, em algum momento de sua vida, necessitará de atenção ou terá que prestar algum tipo de cuidado a alguém, ou seja, ao longo de nossas vidas seremos provedores e beneficiários do trabalho de cuidado.

Não há novatas no tema. Textos obrigatórios, em outras publicações, revelam caminhos já trilhados com firmeza. Se nos ativermos a anos recentes, Helena Hirata e Nadya Guimarães (20 I 2: I) apresentaram o tema a novos leitores e leitoras: "cuidar do outro, preocupar-se, estar atento às suas necessidades, todos esses diferentes significados [...] estão presentes na definição do [cuida- 
do]". Na obra Cuidado e cuidadoras: as várias faces do trabalho do care, organizada por Helena Hirata e Nadya Araujo Guimarães (2012), o tema foi cuidadosamente discutido por especialistas brasileiros e estrangeiros. Entre eles, algumas autoras, e um autor, reaparecem na obra que aqui focalizamos; trazem novas leituras, fruto de indagações teóricas revisitadas ou de pesquisas recentes.

Retomemos, porém, a coletânea recentíssima e o texto instaurador de Kergoat (20I6). A "desconstrução do conceito" conduziu-a à formulação de "trabalho do cuidado", empreitada teórica que a autora, juntamente com Hirata e Molinier, empreende há algum tempo. O cuidado não se resume à relação de valor, à valorização do capital. O caminho teórico levou-a a propor uma sofisticada articulação entre relações (rapports) sociais de classe e relações sociais de sexo, como ferramenta para enfrentar e apreender a complexidade das características do cuidado. O nome da ferramenta para articular classe e sexo passa pelo filtro da consubstanciação - não é fácil, ao menos não nos pareceu fácil, apreender a riqueza de tal démarche, ou a proposta teórica da consubstancialidade. São rapports, ou relações sociais de classe e de sexo, que se "interseccionam", que costuram um padrão intersecional. Ou seja, uma trilha teórica árida - ainda que sutil e sedutora. Uma mirada sociológica, diz a autora, terá de superar a noção de que os termos teóricos sexo e classe se interceptam, se interseccionam. Em sua crítica, a chamada interseccionalidade, por sua vez um conceito que daria conta de imbricações de todo tipo (categorias como idade, religião, ou deficiência física, correlacionadas a relações de classe e sexo), pode ser "falsamente" unificadora (p. 20). O questionamento teórico da autora exige, então, um comentário adicional. Confronte-se, inicialmente, sua postulação de que não é suficiente (como interpretação) um estudo concluir que mulheres negras e pobres estão "na intersecção de vários sistemas de dominação". Não há como discordarmos. Nem tampouco se pode discordar, do ponto de vista sociológico, de que seja "indispensável pensar os processos", "rastrear os processos", que estão na origem de tais entrecruzamentos (p. 2I). A nosso ver, o que torna a desafiadora postura teórica de Kergoat (20I6) menos convincente - ainda que sedutora, insistimos - é supor que somente por meio dos termos de "consubstancialidade" possamos alcançar ou reconstruir tais processos. É de supor, por outro lado, que o próprio subtítulo do volume, a alusão a "perspectivas interseccionais", está a sugerir o rendimento teórico de tais perspectivas. A sociologia histórica abre ainda outros caminhos, por certo - a exemplo do capítulo ıo, de Monique Meron (20I6), sobre a categorização do trabalho na França, bem como as análises farta e fortemente empíricas de inúmeros capítulos, como o 6, sobre a mercantilização no (do) feminino, de autoria de Nadya Araujo Guimarães e Murillo Alves de Brito (2016). E talvez ainda caiba argumentar que, entre tais caminhos, não está necessariamente posta uma perspectiva "materialista", como afirma Danièle Kergoat (20I6: I9). A produção do "viver em sociedade", para lembrarmos a transcrição, no texto, de um conceito de Maurice Godelier (p. I8), 
sugere, repetimos, outros caminhos. É o mesmo Godelier, em entrevista recente sobre os Baruya da Nova Guiné, que aduz: "Quanto mais eu avançava, mais descobria que a economia não podia me explicar a formação das sociedades. Algo mais fundamental atravessava todas as práticas, todos os movimentos da existência e dava sentido tanto ao lugar dos homens e das mulheres nos diferentes campos sociais quanto às casas" (Godelier, apud Bert, 2009, p. 4).

O excelente capítulo que se segue, "Sociologia e natureza" (capítulo 2), escrito por Antonio Sérgio A. Guimarães (2016), não apenas traz aos leitores um panorama formidável da discussão teórica, analítica e empírica sobre "classes, raças e sexos", retomando linhas mestras da produção da ciência social brasileira - na ponta da linha, o texto memorável de Roberto Cardoso de Oliveira (I963) sobre "fricção interétnica", que antecipa interseccionalidades e consubstancialidades. Mais que isso, Antonio Sérgio nos dá o tom afinadíssimo de todo o volume organizado por Alice Rangel de Paiva Abreu, Helena Hirata e Maria Rosa Lombardi, isto é, a diversidade de perspectivas, a riqueza de sugestões teóricas e procedimentos empíricos sobre o tema gênero e trabalho. Justamente nesse curto mas incisivo capítulo, encontramos a sugestão de que, dentre as teorias feministas - cuja fecundidade, note-se, não está subsumida a uma única perspectiva teórica - destaca-se a holista, que concebe as determinações "intrinsicamente articuladas ou imbricadas" das relações de poder e de sexo. Estamos de volta, já se vê, às formulações teóricas de Danièle Kergoat, ainda que sob outro prisma.

\section{II}

Importante é reter, ao longo dos vários capítulos, o foco teórico, analítico e densamente empírico sobre as desigualdades e discriminações sistemáticas da divisão social do trabalho entre os sexos e as reflexões, ao longo de todo o volume, sobre as hierarquias que constituem "sistemas de gênero". Se procurarmos entender a historicidade de tais sistemas, estaremos próximos de captar as razões de o trabalho de cuidado estar restrito basicamente à mulher. Para Adriana Piscitelli (capítulo 4), a constituição de sistemas de gênero, no tocante ao mundo do trabalho, produziu intersecções responsáveis por "destinar" a mulher a certos "nichos ocupacionais". Se retomarmos Godelier, o "viver em sociedade" veio historicamente a conferir legitimidade a um amplo espectro de atividades laborais, mas não ofereceu à mulher a opção de querer ou não exercer a função de cuidar do outro.

Instigante nesse sentido, o trabalho de Piscitelli sobre as narrativas das trabalhadoras sexuais brasileiras na Espanha. "Nesses setores altamente mercantilizados da indústria do sexo, as qualidades que essas entrevistadas destacam para afirmar a 'brasilidade' são a afetuosidade, o cuidado, a amabilidade e a alegria" (p. 5I, ênfase nossa), características que refletem, segundo a autora, o caráter por assim dizer doméstico, "carinhoso", das relações estabelecidas entre essas mulheres e seus clientes nesse nicho ocupacional agora legalizado 
em muitos países. Renata Gonçalves, responsável pela oportuna vinheta na segunda capa, classifica as mulheres migrantes e "trabalhadoras do sexo" como "mulheres globais" - que "ganham destaque nesse mercado onde as coerções estruturais persistem com forte apelo aos atributos femininos".

A injusta organização do cuidado está fortemente presente nas discussões dos capítulos de Rachel Silvera - O salário das mulheres na França (capítulo 7) - e de Lena Lavinas, Ana Carolina Cordilha \& Gabriela Freitas da Cruz - Assimetrias de gênero no mercado de trabalho no Brasil (capítulo 8). Estão ali discutidas, em particular, as complexas relações trabalhistas e a magnitude das diferenças salariais de gênero, tempo de trabalho e inserção ocupacional. Participar no mercado de trabalho, já nos ensina há décadas a perversa trajetória brasileira de "informalidade" e precariedade, não significa ter reconhecimento profissional. Entre brasileiras e também entre francesas, a presença em ocupações formais ou informais de tempo parcial, (in)justamente maior nos setores considerados "feminizados", combina, sem conciliações, trabalho remunerado e obrigações domésticas. O tempo parcial traz salários parciais, progressões de carreiras parciais e, consequentemente, aposentadorias parciais, que aprofundam ainda mais o hiato salarial entre os sexos. No outro extremo, o acesso das mulheres a cargos de decisão e empregos mais bem remunerados continua limitado, tanto no Brasil quanto na França. "Nos dois países, mesmo quando alcançam lócus de poder", poderão ainda assim ter menor prestígio, lembra Renata Gonçalves; ou para conquistá-lo, advertia Gilberto Freyre em frase clássica, tornam-se "sociologicamente" homens.

Importante referir os capítulos que discutem o uso do tempo e as tensões entre a vida pessoal, familiar e laboral das mulheres. Laís Abramo e Maria Elena Valenzuela abrem o capítulo 9 focalizando possíveis câmbios nas relações sociais: "a possibilidade de uma articulação mais equilibrada entre o trabalho e a vida pessoal e familiar é uma dimensão estratégica central para a promoção da igualdade de gênero no mundo do trabalho e está intrinsecamente relacionada ao conceito de trabalho decente" (Abreu, Hirata \& Lombardi, 20 I6: I I3). A noção de trabalho 'decente', bem sabemos, traz implicações sérias para atividades laborais consideradas 'indecentes'. Mas são representações sociais muito presentes no âmbito das famílias, ainda que esgarcem a própria noção de cuidado. Isto posto, como conciliar, ou melhor, como fazer bom uso do tempo em tarefas que a mulher desempenha em casa, no trabalho ou no cuidado de um familiar idoso? Essa é uma questão importante para núcleos familiares em tantas regiões mundo afora, não apenas na América Latina (foco do capítulo), o que torna o ensaio particularmente relevante, ao abordar o número crescente das populações idosas e dos domicílios nos quais as mulheres são "a pessoa de referência". Daí advêm novas pressões sobre a divisão do trabalho e as necessidades de cuidados, em que se destacam dois pontos fundamentais: o primeiro diz respeito à incidência e à prevalência de problemas relacionados à velhice, como as doenças 
crônicas e as deficiências ou incapacidades funcionais a elas relacionadas. O segundo ponto que se observa - como uma característica mundial - é a transferência do tratamento das condições crônicas do hospital para o domicílio, exigindo maior presença de cuidadores - cuidadoras! - no espaço doméstico.

Tema caro à sociologia do trabalho, a situação das "domésticas" também as aproxima das cuidadoras, pois não é raro que elas próprias se envolvam no cuidado ao idoso, nas residências em que se empregam. As domésticas constituem o elo mais frágil dos serviços remunerados. A análise abre espaço à discussão das relações de cuidado entre classe, raça e sexo. A situação dessas trabalhadoras é discutida nos textos de Monique Meron (20I6), "Trabalho remunerado e trabalho doméstico na França”, e de Maria Betânia Ávila (20I6), "O tempo do trabalho doméstico remunerado: entre cidadania e servidão" (capítulos io e I I). No capítulo escrito por Meron, o foco se concentra nas classes urbanas. Em que pesem as mudanças nas atribuições do trabalho doméstico, as atividades consideradas "clássicas", lembra a autora, continuam realizadas por mãos femininas. As diferenças entre homens e mulheres se reduziram, em casais com filhos na França (algo que vai-se tornando frequente, pouco a pouco, no Brasil), mas persiste a distância no uso do tempo no tocante às responsabilidades de gênero - as mulheres situando-se "mais presentes no 'núcleo duro' das atividades domésticas” (p. I32).

Maria Betânia Ávila discute a situação das trabalhadoras domésticas no Brasil, que representava mais de $90 \%$ da força de trabalho. Desse total, diz a autora, 6I\% é de mulheres negras. Cabe recuperar a pergunta de Renata Gonçalves, "por que nessa ocupação o percentual de mulheres negras é maior?". Impõe-se o retorno ao ensaio de Antonio Sérgio A. Guimarães, por conferir ao substrato histórico - à herança escravista - o obstáculo às relações e aos direitos trabalhistas no Brasil, como elemento central "da tensão entre cidadania e servidão" (Ávila, 20I6: I38). Ávila nota, com precisão, que os avanços trabalhistas acirram as contradições nas relações sociais de sexo/gênero no espaço doméstico. Talvez se deva observar, contudo, que não estamos apenas diante da dialética das contradições entre as relações sociais de classe, raça e sexo, ressaltadas pela autora, mas importa resguardar o papel complicador desempenhado, no âmbito cultural - para além da compreensão materialista -, pelo estigma e preconceito reproduzidos no cotidiano do trabalho doméstico. Não será demais defender que os conceitos feministas materialistas, "ferramentas poderosas" para pensar as transformações do trabalho, como bem salientou Jules Falquet (capítulo 3), não bastam para a compreensão das relações de dominação, estigma e distanciamento no cotidiano, para cujo objetivo as teorias interacionistas se oferecem como ferramenta igualmente poderosa.

Se retomarmos as questões do cuidado, toda a Parte III da obra, dedicada a "trabalho e uso do tempo" (capítulos 9 a I I) remete a questões absolutamente prementes, que dizem respeito não apenas à América Latina e Europa, mas à América do Norte e a outros continentes. Os dados indicam oferta cada 
vez mais insuficiente de serviços formais à pessoa idosa e a persistência de desigual distribuição do trabalho de cuidado entre homens e mulheres. Se retomarmos, na Parte III, a divisão sexual das tarefas domésticas, suas inter-relações com as obrigações do cuidar e com os problemas graves que se anunciam, será sempre importante termos presentes os fatores, contextos e processos culturais, demográficos e sociais que ainda levam, no quadro do envelhecimento mundial, à designação da mulher para assumir o cuidado do idoso incapacitado (cf. Faria, Calábria \& Alves, 20I6).

Os capítulos que se seguem trazem reflexões importantes sobre a atuação feminina nos vários mercados de hegemonia masculina, como, por exemplo, na ciência e tecnologia, na aviação, no campo da música, tanto no Brasil quanto na França. Discute-se, na Parte IV (capítulos I 2 a I5), a luta por espaços nos quais as mulheres estão em clara minoria em setores tradicionalmente masculinos; os desafios diante das desigualdades de gênero na distribuição de poder e recursos, bem como a forma possível de superá-las, e, em especial, o desafio de potencializar o feminino na esfera profissional - isto é, nos termos adotados por organismos internacionais, como o Banco Mundial "a capacidade das mulheres de fazer escolhas estratégicas em suas vidas para resolver seus problemas” (Sorj, 2016).

No capítulo I5, Superar limites nas carreiras de mulheres musicistas, Liliana Segnini mostra as discrepâncias, a diferença numérica da participação feminina e masculina nas carreiras de pianista, violinista e em postos de prestígio em orquestras, bem como, com base em entrevistas, os obstáculos enfrentados para a conquista de reconhecimento e prestígio; "muito trabalho, competição e avaliação permanente exigem um esforço constante para conquistar e permanecer no seu posto de trabalho" (p. I86). Por outro lado, como indicam, por contraste, os artigos dos capítulos comentados a seguir, ainda é entre musicistas que a carreira solo se faz possível, e - diferentemente de mulheres (e homens!) nas carreiras científicas - a inserção no mundo do trabalho em grandes centros europeus se abre aqui e ali, casos em que diferenciações de gênero e classe social podem se atenuar. Talvez não para formações orquestrais? Fato é que o texto levanta tantas pistas, revela um tema ainda tão pouco explorado, que nos inclinamos por pedir bis: ao bisar, a autora alinharia talvez outros caminhos interpretativos de interesse especial para músicos intérpretes, como o artigo extraordinário de Robert R. Alford e Andras Szanto (I996), sobre "the experience of pain" no mundo profissional do piano. Publicado em I996, em Theory and Society, o texto pede tradução urgente. Textos como o de Alford e Szanto marca(ra) $m$ época e exploram questões sutis e cruciais, sobre o exercício de juízos estéticos e a construção de identidades profissionais e imagens de self entre musicistas. São questões que pedem, talvez, outros recortes interpretativos, além do objetivo teórico explicitado por Liliana nas primeiras linhas de seu ensaio.

Como sugerido acima, passemos aos capítulos que focalizam, precipuamente, as carreiras técnicas e científicas. A presença feminina em ciência e 
tecnologia, no tocante ao Brasil, é focalizada no capítulo I2, de autoria de Alice Rangel de Paiva Abreu e colaboradoras. Os capítulos i3 (por Nathalie Lapeyre) e I 4 (por Maria Rosa Lombardi e Débora de Fina Gonzalez) abordam a inserção em empresas da área aeronáutica (França) e engenharias (Brasil). Fincados em firme terreno empírico, os textos têm implicações que extrapolam o terreno das estatísticas para alcançar debates e polêmicas internacionais, particularmente quanto à "participação da mulher na sociedade de conhecimento" (p. I52). Uma observação central, no capítulo I 2, é sobre a participação destacada na reprodução social - saúde e educação -, em contaste com a menor participação em "criação e inovação" (p. I52-I53). Persiste, segundo as autoras, a baixa participação feminina nas engenharias. Ao lado de sugestões de política social compensatórias e universalistas, propõem-se programas endereçados especificamente à promoção do interesse feminino nas engenharias, na física, na matemática. No capítulo de Lombardi e Gonzalez, a noção de cultura profissional (p. I79) é a linha demarcatória entre hierarquias de gênero construídas num cenário situacional - ou nos rituais de exclusão/inclusão e (des)classificação - em contraste com explicações que apontam "inclinações biológicas" ou "intrinsic aptitudes", de modo a descartar fatores sociais e culturais que afetam escolhas pessoais.

Um episódio marcou o mundo acadêmico norte-americano, em fevereiro de 2005: a declaração do então reitor da Universidade de Harvard, em debate público, que atribuía a "descobertas" em genética comportamental uma inaptidão feminina em ciências e engenharias, o que as demoveria de posições de liderança nas áreas técnicas. As declarações provocaram uma reação enérgica, um voto de no-confidence do corpo docente da universidade, que levaram por fim à renúncia do reitor. Menos importante do que julgar os valores e atitudes da elite de uma universidade da Ivy League sobre a presença da mulher nas carreiras científicas, seria compreender como o país que estabelece quotas e ações afirmativas há décadas, não conseguiu se livrar do uso de "evidências científicas" para encobrir arraigadas ideologias sobre a mulher. Peter Marris, o sociólogo inglês que lecionou em Berkeley e Yale, atribuiu à politics of uncertainty (título de seu livro fundamental) a compulsão generalizada de planejadores por "encontrar" evidências em terrenos marcados, de fato, pela incerteza.

\section{III}

As portas que conduzem ao cuidado são transpostas nos capítulos finais. Será tarefa menos árdua abri-las agora, com a ajuda dos capítulos iniciais da obra, sobre as imbricações e interseccionalidades entre o care e os processos relativos a classes, raças e sexos. As partes V e VI, totalmente voltadas para temas e problemas do cuidado, são dedicadas à discussão das condições sociais, econômicas e políticas sob as quais a atividade do cuidar é oferecida, organizada e vivenciada. As análises se abrem facilmente à leitura, permitindo o entrecruzamento entre fatos e fontes em diferentes níveis e cenários. 
De partida, Helena Hirata oferece-nos uma cartografia sobre trabalhadoras do cuidado domiciliar no Brasil e na França, em seções simples, diretas e informativas, com base em entrevistas realizadas com cuidadoras domiciliares. Revela-se, aqui, a precariedade das condições de trabalho na Europa entre trabalhadoras migrantes, não raro sem documentos, e no Brasil, por empregadas domésticas e faxineiras. Particularmente no Brasil, a cuidadora se insere e se fragiliza nessa esfera privada de cuidados, em uma relação não institucionalizada, que opera ainda sobre uma camada tênue de confiança interpessoal.

Como o tema do cuidado é central às duas partes finais da obra, uma breve digressão conceitual talvez devesse antecipar o texto de Helena, para leituras de primeira mão. Esse é por certo um ponto menor, para ser considerado em uma reedição da presente coletânea. O que importa, no momento, é a qualidade e transparência dos escritos de fundo analítico, que se seguem ao capítulo I6. Nessa espécie de antessala para os conceitos da coletânea referidos ao cuidado, o texto de Aurélie Damamme (capítulo I7) introduz o tema dos disability studies, a nosso ver carecendo de melhor "sintonia fina" nos vários contextos da colaboração França-Brasil. Merece destaque a ênfase no "tomar a palavra no lugar do outro" não somente por evocar outras démarches em que as ciências humanas se dedicam a falar "pelo outro" enfraquecido (la visión y la memoria de los vencidos), mas para trazer à cena a colaboração entre os estudos (não apenas feministas) sobre o handicap e a ética do cuidado. Nesse capítulo, a autora deplora o "círculo vicioso" da depreciação do cuidado do deficiente, "que vai da pessoa enfraquecida àquela que desta se ocupa", nas palavras da socióloga Patricia Paperman, citada no estudo. Sublinha-se também a contribuição inestimável da socióloga Evelyn Nakano Glenn (20I0), em seu pleito por uma caring society, defendido em Forced to care: coercion and caregiving in America, livro que discute o papel subalterno desempenhado pelas cuidadoras (particularmente negras e hispânicas) nos Estados Unidos.

As relações de confiança e desconfiança são evocadas no capítulo seguinte, por Angelo Soares, por meio de atraente fenomenologia do cuidado. Com base em discussões de caráter fenomenológico sobre o cuidar (Milton Mayeroff, On Caring, obra publicada em I97 I, em tradução infeliz no Brasil) e em estudos sociológicos de Niklas Luhmann sobre o conceito de trust, o ensaio mostra de que modo a sociabilidade do cuidado domiciliar se projeta progressivamente, do universo de laços de confiança interpessoais para laços (ainda que precariamente) institucionalizados, algo que Flavien Le Bouter (20I4) já denominou um caminho "de la familiarité à la confiance systémique". Os sentimentos mútuos se revelam, em qualquer dos casos, como o cerne da relação do cuidado, dada a proximidade e o estabelecimento de relações diádicas ou interpessoais (Faria, Alves \& Amaral, 20I6).

Um dos capítulos finais da coletânea por certo ensejará uma leitura transversal e um olhar atento a outro, ambos sutilmente entrelaçados. São eles, 
primeiramente aquele intitulado "Carinho, limpeza e cuidado" entre migrantes brasileiras na Espanha (capítulo 4, Piscitelli) e, em contraponto, o capítulo que se segue ao de Angelo Soares, assinado por Luz Arango (capítulo I9), sobre o cuidado nos serviços estéticos para a clientela negra no Brasil. Esse capítulo retrata a "beleza negra", cultivada nos salões conhecidos também como Beleza Natural (BN). Os dois capítulos evocam autoimagens e cuidado do self. Arango sugere que os "salões BN" refletem "uma estratégia econômica e cultural" das classes populares urbanas (p. 230-23I). Em observação arguta, a autora afirma que esses cuidados estéticos envolvem também "as identidades negras e mestiças [...] em uma ordem social que permanece racista" (p. 23I). Igualmente sagaz é a observação de Piscitelli, em sua pesquisa com trabalhadoras sexuais na Europa, de que as brasileiras, a exemplo da "morena" por ela entrevistada, associavam "carinho, cuidado e limpeza" a certa especificidade identitária, à "corporificação de qualidades que resultaram vantajosas" (p. 55). Em uma sociedade racista, ou fortemente racialista, os mecanismos de mobilidade ascendente para a mulher negra e mestiça das classes populares, aqui como no exterior, parecem envolver estratégias a um tempo de defesa do self e de risk-taking. O "salão", nessa perspectiva, parece operar como um cuidado estético de amplo alcance, de afirmação e projeção em papéis sociais de diversificados mundos sociais. Tal diversificação nos parece realçar um mecanismo de ascenção ou mobilidade para as classes populares de modo geral, não se restringindo ao mundo da mulher "negra" ou "mestiça".

"Le sexe du travail" e "le travail du sexe" alcançam imbricações e correlações sutilmente captadas nessa seção. Em sequência é a vez de um autor, Marc Bessin, realizar uma análise sofisticada sobre os "enigmas fenomenológicos da presença”. O capítulo 20 acena com várias leituras, mas a leitura da migração, como fenômeno de presença/ausência, será das mais cativantes do ponto de vista sociológico. Se nos for permitido novo contraponto com o texto de Piscitelli, desta feita com o ensaio de Bessin, a idade, na "imbricação das relações sociais", fornece o limite temporal para a atuação das trabalhadoras sexuais na Espanha, que se dedicam ao cuidado estético do corpo e ao cuidado na relação com outro corpo. Bessin repõe a questão migratória sob uma grandeangular ao situar a migrante europeia como o elo de famílias transnacionais, que se formam a partir de várias modalidades de trabalho e que contam com remessas em dinheiro, retornos, ausências, atividades de risco, telefonemas... É o caso, lembra, de migrantes "transnacionais" que irão cuidar de idosos ricos, de crianças pequenas etc. Contudo, em qualquer caso, incluindo o das trabalhadoras de Piscitelli, estamos diante de um cuidado globalizado de múltiplas faces, que brotam de uma "circulação internacional de afetos" (p. 240). Essa é uma das reflexões particularmente felizes de todo o ensaio.

A proximidade entre o capítulo de Bessin e o que se segue (capítulo 2I), escrito por Guita G. Debert, salta aos olhos. Guita discute as políticas públicas 
diante do envelhecimento, no Brasil. Norbert Elias é, aqui, uma referência fundamental, pela riqueza de sugestões teóricas e analíticas sobre a morte e os processos e situações do envelhecer. A idade, em sua longa duração, envolve sistemas de expectativas e antecipações de cuidado, para recorrermos novamente a Bessin. Elias foi um mestre ao abordar tais configurações e suas implicações sobre o cuidado, tanto como problema de família quanto como questão de Estado. Particularmente em sociedades em que o cuidado da família possuía ou possui forte tradição, a entrada de mulheres, antes cuidadoras de "seus" idosos, no mercado de trabalho, concomitante ao próprio crescimento da população idosa, projeta problemas sociais e terríveis frustrações familiares no mundo privado - e não remunerado - do acolhimento ao idoso. A autora, ao demarcar tais contrastes e tensões entre o público e o privado, chama a atenção para os avanços na construção de políticas sociais para os idosos, a exemplo do Estatuto dos Idosos, de 2003; no entanto, insiste Guita Debert, a provisão de serviços contemplados em tais programas e políticas raramente passa por avaliações quanto à abrangência ou eficácia. Talvez o aspecto mais contundente da temporalidade seja a mercantilização dos chamados jovens idosos e a progressiva invisibilidade dos mais velhos: as políticas e programas sociais "tendem a tornar invisíveis os dramas que caracterizam os estágios mais avançados do envelhecimento" (p. 252). Se Marc Bessin discute os contornos de uma "política da presença", Guita Debert trataria de lembrar, pelo avesso, uma política de ausências. É como se a violência contra o idoso - a tragédia que se banaliza e alcança a trama de novelas na TV - fosse apenas uma face da ausência de políticas concretas e ativas. A outra face, já se vê, se refletiu na trágica ausência de programas e políticas que efetivamente deem conta da violência contra o jovem. Esse será o tema do capítulo 22, em que cuidado e violência são trabalhados por Bila Sorj, a partir de uma pesquisa com Mulheres da Paz (MP), um programa social de prevenção e ações afirmativas, em favelas e periferias no Rio de Janeiro, iniciado em 2008 e encerrado alguns anos depois.

O programa (MP), desencadeado pelo Ministério da Justiça no Rio de Janeiro, envolveu o treinamento de mulheres residentes em periferias e favelas para atuar junto a jovens em "situação de risco", de modo a encaminhá-los a projetos de capacitação profissional. O Programa foi inspirado, segundo Sorj, na ideia de promover e institucionalizar os movimentos de mães - a exemplo das Mães de Acari, um grupo de mulheres da Zona Norte carioca que buscava punição aos assassinos de seus filhos, em r 990 . Ainda que antecipasse o engajamento das mulheres na promoção de uma "cultura da paz" (p. 260), seus objetivos não foram alcançados. Vários foram os obstáculos, entre esses, sempre citados, os conflitos de interesses e o despreparo, na capacitação, para interagir com os jovens. O capítulo discorre sobre as limitações, potencialidades e dificuldades de consolidação e expansão de um programa que poderia ter tido sucesso, mas malogrou. A autora vai à raiz dos problemas enfrentados na 
formação de 'cidadanias ativas', ao lembrar que os formuladores de políticas tendem a considerar os bairros pobres comunidades integradas, quando, de fato, "são espaços sociais heterogêneos", em que por vezes se chocam valores, interesses e normas locais. Por fim, Bila Sorj mostra como ações de promoção de valores de cidadania e participação entre mulheres responsáveis pelo cuidado aos jovens tende a criar expectativas (e antecipações de cuidado, se recorrermos a Marc Bessin) entre os jovens e também entre as mulheres atuantes no Programa. "Elas demandam as mesmas oportunidades de inserção no mercado de trabalho oferecidas aos jovens" (p. 264).

Os dois capítulos abordados voltam-se para questões de envelhecimento (Debert) e violência contra o jovem (Sorj) no Brasil. Contudo, uma segunda leitura poderá aquilatar as possibilidades e aplicações de ambos os estudos para o cenário europeu e, em particular, para a França. O caso dos programas de prevenção e enfrentamento de "situações de risco" entre os jovens pede, desde logo, uma reflexão sobre as escolas na França, diante do desafio posto pelas novas gerações - e não apenas pelas correntes imigratórias recentes -, ainda mais heterogêneas do que no Brasil, quanto a raça/origem étnica, religião e nacionalidades de origem.

Por razões similares, isto é, por compartilhar questões cruciais, o capítulo 23, que encerra o volume, é absolutamente relevante para uma leitura de "problemas brasileiros" e "franceses". O que pretende a autora, Florence JanyCatrice, é colocar em questão os modelos de imputação de valor monetário ou econômico ao cuidado. Critica-se a desvalorização daquele cuidado que não pode ser contado; a atividade de atenção solidária que não é quantificável. JanyCatrice não aceita a "desqualificação estrutural", pelos modelos adotados por avaliadores de programas, de atividades de difícil quantificação que, no entanto, são essenciais à convivência humana. O ensaio postula a necessidade de consideração dos benefícios coletivos do cuidado, a partir de outro modelo avaliativo. "Não faremos uma outra economia sem refletir sobre o laço entre economia e democracia" (p. 274). Ou, talvez, sem refletir sobre laços? Conta-se o caso de uma paciente de 90 anos, no Rio de Janeiro, que se deslocava para um consultório distante de seu bairro e se recusava a escolher outro dentista mais próximo. A profissional, que a atendia já há muito anos, ouviu-a justificar: "Minha filha, eu sou de uma época em que se faziam laços" (Rôças e Rego, 20I6: 66).

\section{IV}

Coletâneas que denotam o "cuidado" em sua consecução, competência na organização do conjunto e produção autoral de excelente qualidade exigem uma resenha igualmente cuidadosa. Foi o que procuramos realizar. O que esperamos é que haja nova edição em breve, como merecem organizadoras e autoras. Será bem-vinda a preparação de um índice onomástico para a segunda edição. Nessa ocasião, do mesmo modo como a comunidade científica tem procurado rechaçar as incursões das áreas biomédicas sobre a conduta ética da pesquisa 
nas ciências sociais, caberia talvez recusarmos imposições de normas técnicas sobre a construção das referências bibliográficas. Como sabemos, também provém, historicamente, da área médica o "modo de citar" autores e seus nomes apenas na inicial. Na tradição das velhas escolas de medicina, não havia dúvidas sobre o gênero dos catedráticos. Hoje, a adoção acrítica de "normas e técnicas" de tempos antigos acarreta situações curiosas, como o ocorrido com uma aluna de enfermagem, na disciplina de sociologia, a quem eu indaguei, em sala de aula, de onde retirara uma citação em seu trabalho de conclusão sobre o envelhecimento. "DO Debert", respondeu. O artigo, corretamente citado pela aluna, era de G.G. Debert.

Recebido em 2/3/2017 | Aceito em I8/6/2017

Luiz Antonio de Castro Santos é sociólogo, com PhD em sociologia pela Universidade de Harvard. Na área de saúde e demografia, é mestre pela School of Public Health na mesma universidade. Aposentou-se como professor-associado, no Instituto de Medicina Social da Uerj. Como visitante sênior na Universidade Federal do Sul da Bahia, integrou-se ao programa nacional do Mestrado Profissional em Saúde da Família, do qual é, presentemente, docente permanente. Publicou Contrapontos: ensaios sobre saúde e sociedade (2013)

Lina Faria é fisioterapeuta, historiadora e doutora em saúde coletiva pelo Instituto de Medicina Social da Uerj, com pós-doutorado em políticas de ciência e tecnologia pela Unicamp. Atualmente, é professora adjunta no Centro de Formação em Saúde da Universidade

Federal do Sul da Bahia, no Campus de Porto Seguro. Organizou recentemente (com Luciana Calábria e Waneska Alves) a coletânea intitulada Envelhecimento: um olhar interdisciplinar (2016). 


\section{NOTA}

I No original: "Plus j'avançais et plus je trouvais que l'économie ne pouvait pas m'expliquer la formation des sociétés. Quelque chose de plus fondamental traversait toutes les pratiques, tous les mouvements de l'existence et donnait sens aussi bien à la place des hommes et des femmes dans les différents champs sociaux que dans les maisons".

\section{REFERÊNCIAS BIBLIOGRÁFICAS}

Abramo, Laís \& Valenzuela, Maria Elena. (2or6). Tempo de trabalho remunerado e não remunerado na América Latina: uma repartição desigual. In: Abreu, Alice Rangel de Paiva; Hirata, Helena \& Lombardi, Maria Rosa (orgs.). Gênero e trabalho no Brasil e na França: perspectivas interseccionais. São Paulo: Boitempo.

Abreu, Alice Rangel de Paiva; Hirata, Helena \& Lombardi, Maria Rosa (orgs.). (2016). Gênero e trabalho no Brasil e na França: perspectivas interseccionais. São Paulo: Boitempo.

Abreu, Alice Rangel de Paiva e cols. (20I6). Presença feminina em ciência e tecnologia no Brasil. In: Abreu, Alice Rangel de Paiva; Hirata, Helena \& Lombardi, Maria Rosa (orgs.). Gênero e trabalho no Brasil e na França: perspectivas interseccionais. São Paulo: Boitempo.

Alford, Robert R. \& Szanto, Andras. (I996). The experience of pain. Theory and Society, 25/I, p. I-44.

Arango, Luz. Cuidado, emoções e condições de trabalho nos serviços estéticos no Brasil (2016). In: Abreu, Alice Rangel de Paiva; Hirata, Helena \& Lombardi, Maria Rosa (orgs.). Gênero e trabalho no Brasil e na França: perspectivas interseccionais. São Paulo: Boitempo.

Ávila, Maria Betânia. (20I6). O tempo do trabalho doméstico remunerado: entre cidadania e servidão. In: Abreu, Alice Rangel de Paiva; Hirata, Helena \& Lombardi, Maria Rosa (orgs.). Gênero e trabalho no Brasil e na França: perspectivas interseccionais. São Paulo: Boitempo.

Bert, Jean-François. (2009). Entretien avec Maurice Godelier. Le Portique, I9 Disponível em <http://leportique.revues.org/I26I $>$. Acesso em I5 nov. 2017. 
Bessin, Marc. (20I6). Política da presença: as questões temporais e sexuadas do cuidado. In: Abreu, Alice Rangel de Paiva; Hirata, Helena \& Lombardi, Maria Rosa (orgs.). Gênero e trabalho no Brasil e na França: perspectivas interseccionais. São Paulo: Boitempo.

Damamme, Aurélie. (20I6). O cuidado em suas temporalidades e seus atores na França. In: Abreu, Alice Rangel de Paiva; Hirata, Helena \& Lombardi, Maria Rosa (orgs.). Gênero e trabalho no Brasil e na França: perspectivas interseccionais. São Paulo: Boitempo.

Debert, Guita. (20I6). Políticas públicas diante do envelhecimento. In: Abreu, Alice Rangel de Paiva; Hirata, Helena \& Lombardi, Maria Rosa (orgs.). Gênero e trabalho no Brasil e na França: perspectivas interseccionais. São Paulo: Boitempo. Falquet, Jules. (20I6). Transformações do trabalho das mulheres: liberação ou novas formas de apropriação? In: Abreu, Alice Rangel de Paiva; Hirata, Helena \& Lombardi, Maria Rosa (orgs.). Gênero e trabalho no Brasil e na França: perspectivas interseccionais. São Paulo: Boitempo.

Faria, Lina; Alves, Waneska \& Amaral, Sonia (2016). Sentimento mútuo: as relações de cuidar e ser cuidado no domicílio. In: Faria, Lina; Calábria, Luciana \& Alves, Waneska. Envelhecimento: um olhar interdisciplinar. São Paulo: Hucitec.

Faria, Lina; Calábria, Luciana \&. Alves, Waneska (2016). Envelhecimento: um olhar interdisciplinar. São Paulo: Hucitec. Glenn, Evelyn Nakano. (2010). Forced to care: coercion and caregiving in America. Cambridge/London: Harvard University Press.

Guimarães, Nadya Araujo \& Brito, Murillo Alves de. (2016). Mercantilização no feminino: a visibilidade do trabalho das mulheres no Brasil. In: Abreu, Alice Rangel de Paiva; Hirata, Helena \& Lombardi, Maria Rosa (orgs.). Gênero e trabalho no Brasil e na França: perspectivas interseccionais. São Paulo: Boitempo.

Hirata, Helena. (20I6). O cuidado em domicílio na França e no Brasil. In: Abreu, Alice Rangel de Paiva; Hirata, Helena \& Lombardi, Maria Rosa (orgs.). Gênero e trabalho no Brasil e na França: perspectivas interseccionais. São Paulo: Boitempo. 
Hirata, Helena. (2012). O trabalho de cuidado aos idosos no Japão e alguns aspectos de comparação internacional. Mediações, I7/2, p. I57-I65. Disponível em <http://www.uel. $\mathrm{br} / \mathrm{revistas} / \mathrm{uel} / \mathrm{index} . \mathrm{php} / \mathrm{mediacoes} / \mathrm{article} / \mathrm{viewFi}$ le/I4027/II838>. Acesso em 7 nov. 2017.

Hirata, Helena \& Guimarães, Nadya A. (2012). Cuidado e cuidadoras. As várias faces do trabalho do care. São Paulo: Atlas.

Jany-Catrice, Florence. (2016). Economia do cuidado e sociedades do bem viver: revisitar nossos modelos. In: Abreu, Alice Rangel de Paiva; Hirata, Helena \& Lombardi, Maria Rosa (orgs.). Gênero e trabalho no Brasil e na França: perspectivas interseccionais. São Paulo: Boitempo.

Kergoat, Danièle (20I6). O cuidado e a imbricação das relações sociais. In: Abreu, Alice Rangel de Paiva; Hirata, Helena \& Lombardi, Maria Rosa (orgs.). Gênero e trabalho no Brasil e na França: perspectivas interseccionais. São Paulo: Boitempo.

Lapeyre, Nathalie. (2016). Aviões e mulheres: política de igualdade profissional em uma empresa aeronáutica na França. In: Abreu, Alice Rangel de Paiva; Hirata, Helena \& Lombardi, Maria Rosa (orgs.). Gênero e trabalho no Brasil e na França: perspectivas interseccionais. São Paulo: Boitempo. Lavinas, Lena; Cordilha, Ana Carolina \& Cruz, Gabriela Freitas da. (20I6). Assimetrias de gênero no mercado de trabalho no Brasil. In: Abreu, Alice Rangel de Paiva; Hirata, Helena \& Lombardi, Maria Rosa (orgs.). Gênero e trabalho no Brasil e na França: perspectivas interseccionais. São Paulo: Boitempo.

Le Bouter, Flavien. (2014) Formes et fonctions de la confiance dans la société moderne. Implications Philosophiques. Disponível em <http://www.implications-philosophiques. org/>. Acesso em 7 nov. 2017.

Lombardi, Maria Rosa \& Gonzalez, Débora de Fina. (2016). Engenharia e gênero: as mutações do último decênio no Brasil. In: Abreu, Alice Rangel de Paiva; Hirata, Helena \& Lombardi, Maria Rosa (orgs.). Gênero e trabalho no Brasil e na França: perspectivas interseccionais. São Paulo: Boitempo. Mayeroff, Milton. (I97I). On caring. New York: Harper \& Row. 
Meron, Monique. Trabalho remunerado e trabalho doméstico na França. In: Abreu, Alice Rangel de Paiva; Hirata, Helena \& Lombardi, Maria Rosa (orgs.). Gênero e trabalho no Brasil e na França: perspectivas interseccionais. São Paulo: Boitempo.

Oliveira, Roberto Cardoso de. (1963), "Aculturación y 'fricción' interétnica”. América Latina, 6/3, p. 33-46.

Piscitelli, Adriana (2016). Carinho, limpeza e cuidado: experiências de migrantes brasileiras. In: Abreu, Alice Rangel de Paiva; Hirata, Helena \& Lombardi, Maria Rosa (orgs.). Gênero e trabalho no Brasil e na França: perspectivas interseccionais. São Paulo: Boitempo.

Rôças, Valéria e Rego, Mauro L. (20I6). Conversa \& cura: desafiando e desfiando histórias. Brasília: Editora Kiron.

Segnini, Liliana. (2016). Superar limites nas carreiras de mulheres musicistas. In: Abreu, Alice Rangel de Paiva; Hirata, Helena \& Lombardi, Maria Rosa (orgs.). Gênero e trabalho no Brasil e na França: perspectivas interseccionais. São Paulo: Boitempo.

Silvera, Rachel. (20I6). O salário das mulheres na França. In: Abreu, Alice Rangel de Paiva; Hirata, Helena \& Lombardi, Maria Rosa (orgs.). Gênero e trabalho no Brasil e na França: perspectivas interseccionais. São Paulo: Boitempo.

Soares, Ângelo. (20I6). Cuidados e confiança. In: Abreu, Alice Rangel de Paiva; Hirata, Helena \& Lombardi, Maria Rosa (orgs.). Gênero e trabalho no Brasil e na França: perspectivas interseccionais. São Paulo: Boitempo.

Sorj, Bila. (2016). O cuidado e a nova agenda de combate à violência no Brasil. In: Abreu, Alice Rangel de Paiva; Hirata, Helena \& Lombardi, Maria Rosa (orgs.). Gênero e trabalho no Brasil e na França: perspectivas interseccionais. São Paulo: Boitempo. 


\section{Palavras-chave}

Trabalho;

cuidado;

gênero;

Brasil;

França.
Keywords

Gender;

work;

caring,

Brazil;

France.
ENSAIO DE LEITURA: INTERSECÇÕES E CORRELAÇÕES NO MUNDO DO TRABALHO E DO CUIDAR (BRASIL/FRANÇA)

\section{Resumo}

O presente ensaio de leitura se insere na linha das avaliações mais densas ou encorpadas dos review essays, composição típica das ciências sociais inglesas e norte-americanas. O foco do ensaio é a obra Gênero e trabalho no Brasil e na França: perspectivas interseccionais, uma coletânea organizada pelas sociólogas Alice Rangel de Paiva Abreu, Helena Hirata e Maria Rosa Lombardi. Procura captar, de modo cuidadoso, o cenário aberto por múltiplos olhares suscitados pelas organizadoras da coletânea. Como foco comum, que dá sentido à diversidade de contribuições, discutem-se os desafios e obstáculos enfrentados por protagonistas, seus movimentos sociais e instituições no mundo da divisão sexual do trabalho e do cuidar. Nossa narrativa procura transmitir a visão geral das complexas relações entre trabalho, cuidado, cidadania, ética, políticas do corpo e políticas sociais mais amplas, no Brasil e na França, abordadas nos capítulos.

REVIEW ESSAY: INTERSECTIONS AND CORRELATIONS IN THE WORLD OF LABOUR AND CARE (BRAZIL/FRANCE)

\section{Abstract}

The present review essay focuses on the volume Gender and Work in Brazil and France: Intersectional Perspectives, edited by the sociologists Alice Rangel de Paiva Abreu, Helena Hirata, and Maria Rosa Lombardi. The review seeks to capture the general picture of the always quite complex relations that constitute and configure the world of gender, work, and caring in those two countries. The chapters in the book are discussed in some detail, so that the readers may glimpse the broad issues touched upon by the authors, including: gender inequalities and social rights; social ethics and social policies; social and sexual relations of power. 